\title{
Nazilli Koşullarına Adapte Olabilecek İleri Pamuk Hatlarının Verim ve Lif Kalite Özelliklerinin Belirlenmesi
}

\author{
Mehmet ÇOBAN ${ }^{1 \infty} \quad$ Süleyman ÇİÇEK ${ }^{1}$ \\ ${ }^{1}$ Pamuk Araştırma Enstitüsü Müdürlüğü Nazilli - Aydın \\ $\triangle$ : coban.mehmet44@gmail.com
}

Geliş (Received): 03.11.2017

Kabul (Accepted): 15.12.2017

\begin{abstract}
ÖZET: $\mathrm{Bu}$ çalışma Nazilli koşullarına iyi adapte olabilecek verim bakımından kabul edilebilir, lif kalitesi bakımından daha iyi çeşit adaylarının geliştirilmesi amacıyla 2011 yılında resiproksuz diallel melez popülasyonlardan seçim yapılan tek bitkiler ile başlamıştır. 2014 ve 2015 yıllarında tek bitki seleksiyonları yapılmış ve çalışmaya 2016 yılında sıra seçimleri yapılarak devam edilmiştir. Melezlemelerde GSN 12, Şahin 2000, BA 308, Lider ve Delcerro çeşitleri ebeveyn olarak kullanılmıştır. 2016 yılında, Nazilli Pamuk Araştırma Enstitüsü Müdürlüğü deneme tarlalarında F5 kademesindeki 140 adet tek bitki Gloria, Claudia, BA 308 ve Şahin 2000 standart çeşit olarak kullanılarak tesadüf bloklarında augmented deneme desenine göre denenerek performansları belirlenmeye çalışılmıştır. Çalışmamızda tek bitkilerin randıman $(\%)$, verim $(\mathrm{kg} / \mathrm{da})$, lif verimi $(\mathrm{kg} / \mathrm{da})$, iplik olabilirlik indeksi (SCI), lif inceliği (mic), lif uzunluğu (mm), üniformite indeksi (UI \%), kısa lif oranı (\%), lif mukavemeti (g/teks), lif esnekliği (\%), lif parlaklığ $(\mathrm{Rd})$ ve elyaf sarılık değeri (+b) özellikleri standart çeşitler ile birlikte incelenerek sıra seçimleri yapılmıştır.

Varyans analizi sonuçlarına göre denemede yer alan genotipler arası farklardan randıman, lif verimi, iplik olabilirlik, lif uzunluğu, lif üniformitesi, lif mukavemeti ve lif esnekliği özellikleri bakımından elde edilen veriler önemli bulunmuştur. İleri hatlardan \%45.5 ile çırçır randımanı bakımından 298 numaralı hattan, $713 \mathrm{~kg}$ ile dekara kütlü verimi bakımından 347 numaralı ileri hattan, $301 \mathrm{~kg}$ ile dekara lif verimi ile 298 numaralı hattan, 192 SCI ile iplik olabilirlik indeksi bakımından 141 numaralı hattan, 4.21 micronaire lif inceliği özelliğinde 42 numaralı hat, 34.34 mm lif uzunluğu, $40.1 \mathrm{~g} /$ teks lif mukavameti ve \%4.8 kısa lif oranı bakımından 141 numaralı hattan elde edilen veriler ön plana çıkmıştır. En iyi elyaf parlaklık değeri 79 Rd ile 73 numaralı hat ve elyaf sarılık değeri bakımından 6.6. +b değeri ile 89 ve 234 numaralı hatlar önemli bulunmuştur. Elde ettiğimiz verilere göre 140 adet tek bitkiden 20 adetinin lif kalite değerleri ve verim unsurları birlikte değerlendirildiğinde sıra olarak seçilmesine ve ileri hat denemeleri kurularak bölge standart çeşitleri ile birlikte denenmesine karar verilmiştir. Bulgular birlikte değerlendirildiğinde verim ve lif kalitesi bakımından bölge standart çeşitlerine göre daha iyi özelliklere sahip olabilecek Türk tekstil sanayisinin kaliteli elyaf ihtiyaçlarını karşılayabilecek çeşit adaylarının geliştirilebileceği sonucuna varılmıştır.

Anahtar Kelimeler: Lif kalitesi, melezleme pamuk, verim.
\end{abstract}

\section{Identification of Yield and Fiber Quality Properties of Some Cotton Lines for Nazilli Conditions}

\begin{abstract}
This study was caried out to identify the superior cotton lines with desirable fiber quality properties with accaeptable yield potential for Nazilli conditions. The study was started with crossing non-reciprpcal diallel matting design with GSN 12, Şahin 2000, BA 308, Lider and Delcerro five cotton varieties in 2011. Single plant selection was started in 2014-2015 and single line selections started in 2016. 140 selected plant was planted augmented design in randomized complete block design with four control varieties (Gloria, Claudia, BA 308 and Şahin 2000) in Cotton Research Institute-Nazilli experimental fields in 2016. Row selection was carried out according to ginning outturn $(\%)$, seed cotton yields $(\mathrm{kg} / \mathrm{da})$, lint yields ( $\mathrm{kg} / \mathrm{da})$, spinning congistency index (SCI), fiber fineness (mic), fiber length (mm), uniformity (UI \%), short fiber index (\%), fiber strength (g/teks), elongation $(\%)$, colour grade, reflectance degree $(\mathrm{Rd})$ ve yellowness $(+\mathrm{b})$.

According to results ginning outturn, lint yields, spinning congistency index, fiber length, uniformity, fiber strength and elongation values was found significant. As a result of conducted research superior lines was determined as line298 with $45.5 \%$ ginning outturn, line-347 with $713 \mathrm{~kg} / \mathrm{da}$ seed cotton yields, line- 298 with $301 \mathrm{~kg} / \mathrm{da}$ lint yields, line42 with 4,21 micronaire fiber fineness, line-73 with 79 reflectance degree, line-89 and line-234 with $6.6+b$ yellowness, line-141 with 192 spinning congistency index, $34.34 \mathrm{~mm}$ fiber length, $40.1 \mathrm{~g} / \mathrm{teks}$ fiber strength and $4.8 \%$ short fiber index. As a result of research in order to improve cotton lines having enhanced for fiber length with acceptable yield potentials 20 row was selected from 140 row due to the fiber characteristics and yields potential.

Key Words: Cotton, Yields, Fiber Quality, Hybridization
\end{abstract}

\section{GíRIŞ}

Pamuk, yüzyıllardır birçok ülkede başta tekstil olmak üzere farklı sanayi kollarının en önemli hammaddesidir. Sentetik lif üretiminin sürekli artmasına karşın dünya tekstil sanayinde kullanılan hammaddeler arasındaki yeri ve önemini korumaktadır. Kullanılan 
dokuma hammaddesinin $\% \quad 60^{\prime} 1$ pamuktan karşılanmaktadır. Tarımı ve sanayisi ile geniş bir iş alanı sağlarken, lifi ile tekstil sanayisine, çiğiti ile yağ sanayisine, küspesi ile hayvancılık sektörüne, ihracatı ile dış ticaretimize çok önemli katkıları olan endüstriyel bir üründür (Anonim, 2010).

Dünya nüfusu ve yaşam standardının artması, gıda maddeleriyle birlikte pamuğun da önemini her geçen gün arttırmaktadır. Türkiye 697.000 ton pamuk üretimi ile dünyada 7. sirada, pamuk tüketiminde 1.393 .000 ton ile Çin, Hindistan, Pakistan ve Bangladeş'in ardından 5. sırada ve dünyada lif pamuk ithal eden ülkeler arasında 784.000 ton ile 5. sirada bulunmaktadır (Anonim, 2017). Türkiye tekstilde gerek üretim miktarı, gerekse ürün kalitesi ile önde gelen ülkelerden birisidir. Tekstil sektörümüzün iş gücü ve enerji kullanımı çok ucuz olan Çin, Pakistan, Hindistan gibi ülkeler ile rekabet edebilmesinin tek yolu kalitesi yüksek ürün üretebilmekten geçmektedir.

Pamuk lifi, diğer bitkisel ve sentetik liflere göre daha fazla tercih edilmekte, dünya tekstil ürünleri üretiminde giderek daha büyük önem kazanmaktadır Ancak Türkiye'de toplam pamuk lifi üretimi tekstil sanayisinin hammadde ihtiyacının gerisinde kalmakta ve her yıl toplam lif üretimi kadar pamuk lifi ithal edilmektedir. $\mathrm{Bu}$ da ülkemiz ekonomisi için ciddi kayıplara sebep olmakta ve tekstil sektörümüzü giderek hammadde temini bakımından dışarıya bağımlı kılmaktadır. Ülkemizin planlı bir şekilde pamuk üretimini verim ve lif kalitesi bakımından arttırması gerekmektedir.

Upland pamukları (Gossypium hirsutum L.), verim potansiyelleri yüksek, vejetasyon süresi orta-uzun, çırçır randımanları >\%39 değerinde ve dünyada yetiştirilen pamukların \%80'inden fazlasını oluştururlar. Dolayısıyla da ülkemiz pamuklarının \%99.5'i Gossypium hirsutum L. türü pamuklardır (Gürel ve ark., 2000) . Ülkemizde pamuk sslah çalışmaları, 1950-60'lı yıllarda başlamış ve bazı çeşitler geliştirilmiş olmasına rağmen ülkemizde sslah edilmiş çeşit sayısı günümüz çiftçi ve tekstil sanayicilerinin ihtiyaç ve taleplerini karşılamaktan oldukça uzak görünmektedir.

Birim alandan elde edilen ürün miktarının ve kalitenin artırılması, pamuk ıslah programlarının öncelikli hedefini oluşturmaktadır (Gençer ve Yelin, 1983). Ancak, 1slah programındaki başarı, amacın iyi belirlenebilmesinin yanında, yapılacak 1slah çalışmasında kullanılacak yöntemin ve bu yöntemler içinde kullanılacak anaçların iyi seçilmesi; anaçlara ilişkin melez kombinasyonlardaki genetik yapılarının iyi bir șekilde kombine edilmesi ile mümkündür. Bu nedenle ıslahçının başarıya ulaşabilmesi için amacını iyi belirleyerek ebeveyn seçiminde dikkatli olmasının yanında, geniş bir varyabilite oluşturarak izlenebilecek ıslah yöntemlerini erken kuşaklarda belirlemesi önem arz etmektedir (Gençer, 1978).

Yüksek verimli ve lif teknolojik özellikleri üstün yeni pamuk çeşitlerinin elde edilmesi için pamuk sslahı çalışmalarının kesintisiz ve yoğun bir şekilde sürdürülmesi gerekmektedir. Son yıllardaki çalışmalar ile birlikte, pamuk veriminin arttırılması ve endüstriyel amaçlara uygun lif teknolojik özelliklerinin geliştirilmesi için klasik ıslah çalışmaları da devam etmektedir.

Gossypium hirsutum L. türüne ait pamuk çeşitlerinin verim ve diğer agronomik özelliklerini koruyarak lif kalite özelliklerini geliştirmek amacıyla yapılan türler arası (Gossypium hirsutum L. x Gossypium barbadense L.) melezleme çalışmalarının oldukça eskiye dayandığ 1 ve ilk melezleme çalışmalarının 1860'lı yıllarında yapıldığ

Gossypium hirsutum L. türüne ait çeşitlerin verim kapasiteleri korunarak, lif kalite özelliklerinin geliştirilmesi amacıyla türler arası melezleme çalışmaları sonucunda Gossypium barbadense L. türüne ait çeşitlerden Gossypium hirsutum L. türüne ait çeşitlere gen aktarabilme şansının bulunduğu ifade edilmiştir (Akdemir ve ark., 2001). Aynı şekilde türler arası melezleme ile lif kalite özelliklerin geliştirilebileceği bildirilmiştir (Culp ve Harrell, 1974; Culp, 1979).

Ülkemiz pamuk tohumculuğu bakımından büyük oranda dışarıya bağımlıdır ve yüksek fiyatlar ödeyerek pamuk tohumluğu temin etmektedir. Pamuk tohumculuğu sektöründe karşılaşılan diğer önemli bir problem ise yaygın olarak tarımı yapılan çeşit sayısının az olmasıdır. Bu çeșitlerin bir çoğu istenilen düzeyde üstün lif kalitesi ile ilgili bütün özellikleri taşımamaktadır. Çiftçilerimize ve sanayicimize alternatif ürünler sunulması gerekmektedir. Bu çalışma lif kalite özellikleri bakımından üstün ve verim potansiyeli kabul edilebilir yeni pamuk ileri hatlarının tespit edilerek, Türk tekstil sanayisinin kaliteli elyaf ihtiyaçlarını karşılayabilecek çeşit adaylarının belirlenmesi amacıyla yapılmıștır.

\section{MATERYAL ve YÖNTEM}

Çalışmada, Gossypium hirsutum L. türüne ait GSN12, Şahin 2000, BA 308 ve Lider çeşitleri ile, [(G. hirsutum х $G$. barbadense $\left.\mathrm{F}_{1}\right)$ × $(G$. arboreum $\mathrm{x}$ G.thurberi x $G$. hirsutum)] türleri arasında yapılan melezleme sonucu geliştirilen lif kalite özellikleri ile üstün Delcerro çeşidi ebeveyn olarak kullanılarak 2011 yılında melezlemeler yapılmıştır. Melez popülasyonlardan 2014 ve 2015 yıllarında tek bitki seleksiyonları yapılmış ve çalışmaya 2016 yılında sıra seçimleri yapılarak devam edilmiştir. 2016 yılında, Nazilli Pamuk Araştırma Enstitüsü Müdürlüğü deneme tarlalarında $\mathrm{F}_{5}$ kademesindeki 140 adet tek bitki ile Gloria, Claudia, BA 308 ve Şahin 2000 standart çeşitler sıra arası $0.7 \mathrm{~m}$, sira üzeri $0.2 \mathrm{~cm}$ ve birer siralı olarak tesadüf bloklarında augmented deneme desenine göre denenerek performansları belirlenmeye çalışılmıştır. Ekimle birlikte taban gübresi olarak $5 \mathrm{~kg} / \mathrm{da}$ kompoze gübre (20 -20 -0) uygulanmıştır. Pamukta birinci sulama yapılmadan hemen öncesinde $9 \mathrm{~kg} / \mathrm{da}$ azot içeren Üre gübresi üst gübre olarak parsellere uygulanmıştır. Denemede üç sulama, iki çapalama ve bir ot kırımı yapılmıştır. Hasat, 15 Ekim 2016 tarihinde el ile parsel başı ve sonundan 1 metrelik bölümlerin kenar tesiri olarak elimine edilmesinden sonra on metre üzerinden 
yapılmıştır.

\section{ARAŞTIRMA SONUÇLARI ve TARTIŞMA}

İncelenen özeliklerin varyans analiz sonuçları, Çizelge 1'de verilmiştir. Çizelge 1'den incelenen özelliklerden verim, lif inceliği ve kısa lif oranı dışındaki tüm karakterler için aralarındaki farklılıkların istatistiki olarak önemli olduğu görülmektedir.

Varyans analizi sonuçlarına göre denemede yer alan genotipler arası farklardan çırçır randımanı, lif verimi, iplik olabilirlik indeksi, lif uzunluğu, lif üniformitesi, lif mukavemeti ve lif esnekliği özellikleri bakımından elde edilen veriler önemli bulunmuștur.

Elde ettiğimiz verilere göre 140 adet tek bitkiden 20 adetinin lif kalite değerleri ve verim unsurları birlikte değerlendirildiğinde sıra olarak seçilmesine ve ileri hat denemeleri kurularak bölge standart çeşitleri ile birlikte denenmesine karar verilmiştir. Bulgular birlikte değerlendirildiğinde verim ve lif kalitesi bakımından bölge standart çeşitlerine göre daha iyi özelliklere sahip olabilecek Türk tekstil sanayisinin kaliteli elyaf ihtiyaçlarını karşılayabilecek çeşit adaylarının geliştirilebileceği sonucuna varılmıştır.

İleri hatlardan \%45.5 ile çırçır randımanı bakımından 298 numaralı hattan, $713 \mathrm{~kg}$ ile dekara kütlü verimi bakımından 347 numaralı ileri hattan, 301 $\mathrm{kg}$ ile dekara lif verimi ile 298 numaralı hattan, 192 SCI ile iplik olabilirlik indeksi bakımından 141 numaralı hattan, 4.21 micronaire lif inceliği özelliğinde 42 numaralı hat, $34.34 \mathrm{~mm}$ lif uzunluğu, $40.1 \mathrm{~g} /$ teks lif mukavameti ve \%4.8 kısa lif oranı bakımından 141 numaralı hattan elde edilen veriler ön plana çıkmıştır.

Çizelge 1. İncelenen Özellikler bakımından varyans analizi sonuçları

\begin{tabular}{lrrrrr} 
& \multicolumn{1}{c}{ Blok } & \multicolumn{1}{c}{ Standart } & $\begin{array}{c}\text { Çeşit } \\
\text { (Standart) }\end{array}$ & \multicolumn{1}{c}{ Hata } & Genel \\
\hline SD & 3 & 4 & 139 & 9 & 155 \\
Randıman & 2.092 & $38.252 *$ & $17.849 *$ & 0.896 & 19.888 \\
Verim & 1090.42 & $17882.08 *$ & 2912.59 & 1398.90 & 4377.62 \\
Lif Verimi & 227.897 & $4.232 .613 *$ & $758.418 *$ & 163.230 & 1.246 .170 \\
SCI & 54.396 & $736.289 *$ & $448.563 *$ & 149.45 & 478.704 \\
Lif İnceliği & 0.056 & 0.192 & 0.193 & 0.088 & 0.198 \\
Lif Uzunluğu & 1.388 & $8.986 *$ & $4.977 *$ & 1.545 & 5.226 \\
Uniformite & 0.439 & $3.766 *$ & $2.271 *$ & 0.739 & 2.341 \\
Kisa Lif Oranı & 0.284 & 3.519 & 0.013 & 1.113 & 2.000 \\
Lif Mukavemeti & 4.086 & $33.694 *$ & $11.118 *$ & 2.720 & 11.696 \\
Lif Esnekliği & 0.102 & 0.327 & $0.471 *$ & 0.157 & 0.466 \\
\hline
\end{tabular}

Çırçır randımanı yönünden seçimi yapılan ileri hatların değerleri \% 36.5 ile $\% 45.5$ arasında değişmekte olup kontrol çeşitlerin ortalaması \%40.9 bulunmuştur. Çırçır randımanı özelliği bakımından genotipler arası fark önemli bulunmuş olup (Karademir vd. 2015) tarafından benzer sonuçlar bildirmiştir. Seçimi yapılan ileri hatlardan 9 tanesinin kontrol çeşitlerin ortalamasından daha yüksek çırçır randımanı değerine sahip olduğu görülmüştür.

Dekara verim bakımından seçimi yapılan ileri hatların değerleri 466 ile $713 \mathrm{~kg} / \mathrm{da}$ arasında değişim göstermiş̧iir. Kontrol çeşitlerin ortalaması $541 \mathrm{~kg} / \mathrm{da}$ olarak bulunmuştur. (Karademir vd. 2015) aksine kütlü pamuk verimi bakımından genotipler arasındaki fark önemsiz bulunmuştur. Seçimi yapılan ileri hatlardan 18 tanesinin kontrol çeşitlerin ortalamasından daha yüksek verime sahip olduğu tespit edilmiştir.

Dekara lif verim bakımından seçimi yapılan ileri hatların değerleri 174 ile $301 \mathrm{~kg} / \mathrm{da}$ arasında değişmekte olup kontrol çeşitlerin ortalamas $222 \mathrm{~kg} / \mathrm{da}$ olarak bulunmuştur. (Karademir vd. 2015) bildirdiklerinin aksine dekara lif verimi bakımından genotipler arasındaki fark önemli bulunmuştur. Seçimi yapılan ileri hatlardan 17 tanesinin kontrol çeşitlerin ortalamasından daha yüksek lif verime sahip olduğu anlaşılmıştır.

İplik olabilirlik indeksi yönünden seçimi yapılan ileri hatların değerleri 131 ile 192 SCI arasında değişmekte olup kontrol çeşitlerin ortalaması 147 SCI bulunmuştur. İplik olabilirlik indeksi özelliğine göre genotipler arasındaki fark (Çiçek vd. 2015) çalışmalarındaki sonuçlara benzer olarak önemli bulunmuştur. Seçimi yapılan ileri hatlardan 13 tanesinin kontrol çeşitlerin ortalamasından daha yüksek iplik olabilirlik indeksine sahip olduğu görülmüştür.

Lif inceliği bakımından seçimi yapılan ileri hatların değerleri 4.21 ile 5.67 micronaire arasında değişim göstermiş olup kontrol çeşitlerin ortalaması 4.88 micronaire olarak bulunmuştur. Genotipler arasındaki fark önemsiz bulunurken (Çiçek vd. 2015) bildirdiklerinin aksine (Karademir vd. 2015) benzer sonuçlar bildirmiştir. Seçimi yapılan ileri hatlardan 9 tanesinin kontrol çeşitlerin ortalamasından daha iyi değere sahip olduğu belirlenmiştir.

Varyans analizi sonuçlarına göre lif uzunluğu özelliği bakımından genotipler arasındaki fark önemli bulunmuştur. Lif uzunluğu bakımından seçimi yapılan ileri hatların değerleri 27.57 ile $34.34 \mathrm{~mm}$ arasında değişmekte olup kontrol çeşitlerin ortalaması $29.73 \mathrm{~mm}$ olarak tespit edilmiştir. Seçimi yapılan ileri hatlardan 16 tanesinin kontrol çeşitlerin ortalamasından daha yüksek lif uzunluğuna sahip olduğu anlaşılmıştır. 
Çizelge 2. İncelenen özellikler yönünden kontrollerin ve seçimi yapılan ileri hatların ortalama değerleri.

\begin{tabular}{|c|c|c|c|c|c|c|c|c|c|c|}
\hline Genotip & $\underset{\%}{\text { Randıman }}$ & $\begin{array}{c}\text { Dekara } \\
\text { Verim (kg) }\end{array}$ & $\begin{array}{c}\text { Lif Verimi } \\
(\mathrm{kg} / \mathrm{da})\end{array}$ & $\begin{array}{c}\text { İplik } \\
\text { Olabilirlik }\end{array}$ & $\begin{array}{c}\text { Lif } \\
\text { İnceliği }\end{array}$ & $\begin{array}{c}\text { Lif } \\
\text { Uzunluğu }\end{array}$ & $\begin{array}{c}\text { Üniformite } \\
(\%)\end{array}$ & $\begin{array}{c}\text { Kisa Lif } \\
\text { Oranı }\end{array}$ & Lif Muk. & $\begin{array}{c}\text { Lif } \\
\text { esnekliği }\end{array}$ \\
\hline 298 & 45,5 & 662 & 301 & 133 & 5,38 & 27,68 & 84,5 & 7,9 & 31,4 & 6,0 \\
\hline 384 & 45,0 & 646 & 291 & 155 & 4,93 & 31,37 & 85,5 & 6,5 & 33,3 & 6,3 \\
\hline 347 & 40,5 & 713 & 289 & 136 & 5,19 & 28,95 & 85,2 & 8,2 & 30,2 & 6,9 \\
\hline 358 & 43,6 & 659 & 287 & 140 & 4,92 & 30,02 & 84,4 & 8,0 & 30,6 & 5,7 \\
\hline 395 & 41,3 & 688 & 284 & 153 & 4,57 & 30,81 & 84,9 & 6,9 & 32,7 & 5,3 \\
\hline 378 & 40,5 & 673 & 272 & 140 & 5,19 & 29,87 & 85,3 & 7,1 & 30,0 & 8,7 \\
\hline 391 & 43,9 & 620 & 272 & 139 & 4,58 & 28,73 & 84,9 & 8,4 & 29,1 & 5,8 \\
\hline 164 & 40,8 & 641 & 262 & 157 & 5,67 & 29,89 & 87,7 & 6,5 & 34,0 & 6,0 \\
\hline 76 & 40,1 & 625 & 250 & 146 & 5,25 & 27,57 & 85,2 & 7,0 & 34,5 & 6,8 \\
\hline 381 & 43,9 & 559 & 245 & 156 & 4,70 & 31,93 & 86,8 & 6,0 & 30,7 & 5,9 \\
\hline 339 & 42,1 & 579 & 244 & 151 & 4,93 & 29,17 & 86,1 & 7,4 & 31,9 & 6,2 \\
\hline 352 & 40,9 & 587 & 240 & 152 & 5,02 & 30,68 & 85,1 & 7,4 & 34,0 & 5,2 \\
\hline 105 & 37,0 & 641 & 237 & 175 & 4,72 & 32,17 & 87,9 & 5,4 & 34,9 & 6,0 \\
\hline 73 & 37,5 & 630 & 236 & 180 & 4,59 & 31,94 & 88,4 & 5,2 & 35,4 & 6,9 \\
\hline 84 & 36,5 & 631 & 230 & 161 & 4,61 & 30,53 & 86,1 & 7,5 & 33,8 & 5,9 \\
\hline 30 & 37,3 & 613 & 229 & 169 & 4,63 & 31,83 & 86,2 & 6,6 & 35,7 & 5,7 \\
\hline 42 & 38,1 & 590 & 225 & 167 & 4,21 & 33,19 & 86,6 & 5,6 & 32,6 & 6,1 \\
\hline 141 & 37,3 & 466 & 174 & 192 & 4,82 & 34,34 & 87,8 & 4,8 & 40,1 & 4,4 \\
\hline 89 & 37,3 & 580 & 216 & 162 & 4,94 & 32,07 & 86,4 & 6,6 & 34,3 & 6,4 \\
\hline 234 & 45,4 & 474 & 216 & 143 & 5,55 & 29,15 & 86,0 & 7,8 & 32,9 & 5,3 \\
\hline Gloria & 41,4 & 630 & 261 & 163 & 4,97 & 31,12 & 85,7 & 6,7 & 36,2 & 6,3 \\
\hline Claudia & 42,8 & 531 & 227 & 156 & 4,98 & 30,41 & 86,1 & 6,7 & 33,4 & 6,0 \\
\hline BA308 & 38,9 & 532 & 207 & 138 & 4,93 & 29,54 & 84,5 & 7,7 & 30,7 & 5,8 \\
\hline Şahin & 40,6 & 472 & 192 & 131 & 4,63 & 27,83 & 84,1 & 8,5 & 28,9 & 6,4 \\
\hline $\mathrm{CV}(\%)$ & 2,5 & 7,01 & 6,22 & 8,08 & 5,9 & 4,07 & 1,00 & 15,4 & 5 & 6,7 \\
\hline $\operatorname{LSD}_{(0.05)}$ & 3,4 & 133,8 & 45,7 & 43,73 & 1,1 & 4,45 & 3,07 & 3,77 & 5,9 & 1,4 \\
\hline
\end{tabular}

Kısa lif oranı bakımından seçimi yapılan ileri hatların değerleri \%4.8 ile 8.4 arasında değişmekte olup kontrol çeşitlerin ortalaması $\% 7.4$ bulunmuştur. Kısa lif oranı bakımından (Karademir vd. 2015) bildirdiklerinin aksine genotipler arasindaki fark önemsiz bulunmuștur. Seçimi yapılan ileri hatlardan 14 tanesinin kontrol çeşitlerin ortalamasından daha iyi kısa lif oranına sahip olduğu görülmüştür.

Lif mukavemeti bakımından seçimi yapılan ileri hatların değerleri 4.21 ile $5.67 \mathrm{~g} /$ teks arasında değişim göstermiş olup kontrol çeşitlerin ortalaması $32.3 \mathrm{~g} / \mathrm{teks}$ olarak bulunmuştur. Genotipler arasındaki farklar (Karademir vd. 2015; Çiçek vd. 2015) sonuçlarına benzer olarak önemli bulunmuştur. Seçimi yapılan ileri hatlardan 13 tanesinin kontrol çeşitlerin ortalamasından daha iyi değere sahip olduğu belirlenmiştir.
Sonuç olarak 140 adet tek bitkiden lif kalitesi ve verim değerleri birlikte değerlendirilerek seçimi yapılan 20 adet ileri hattın bölge standart çeşitleri ile performans denemesi kurulması ile Türk tekstil sanayisinin ihtiyacı olan kabul edilebilir verim potansiyeli ve lif kalitesi iyileştirilmiş pamuk çeşitlerinin geliştirilebileceğine kanısına varılmıştır.

\section{KAYNAKLAR}

Anonim, 2010. Pamuk Raporu. Sanayi ve Ticaret Bakanlığı Teşkilatlandırma Genel Müdürlüğü, Ankara.

Anonim, 2017. Cotton World Markets and Trade, United States Department of Agriculture, Foreign Agricultural Services, September 2017. 
Akdemir, H., Gürel A., Karaday1, H.B. 2001. Ege bölgesi koşullarına uygun uzun-ince elyaflı pamukların adaptasyonu üzerine araştırmalar. Anadolu, Ege Tar. Arş. Ens. Derg., 11 (2): 56-75.

Culp, T.W., Harrell D.C. 1974. Breeding Quality Cotton at the PEE DEE Experiment Station Florence, S.C. USDA ARS-S-30, New Orleans, LA.

Culp, T.W. 1979. Notice to plant breeders and geneticists relative to release of five Noncommercial breeding stocks of extra-long staple upland cotton, Sealand 542, Earlistaple 7, Line F (Hybrid 330), FJA, and FTA. S.C. Agric. Exp. Stn Bull.

Çiçek S., Küçüktaban F., Yazıcı L., Çoban M. 2015. Ege Bölgesi Koşullarında Farklı Pamuk Çeşit Ve Hatlarının Performanslarının Belirlenmesi. Türkiye 11. Tarla Bitkileri Kongresi, 07-10 Eylül, Çanakkale.

Gençer, O. 1978. Gossypium hirsutum L, ve Gossypium barbadense L. Türlerinden Sekiz Pamuk Çeșidinin Diallel Melezlerinde Verim ve Kalite ile İlgili Başlıca Özelliklerin Kalıtımı Üzerinde Araştırmalar. Çukurova Üniversitesi, Ziraat Fakültesi, Doçentlik Tezi, Adana .
Gençer, O. Yelin, D., 1983. Pamuk bitkisinde (Gossypium hirsutum L.) erkencilik kriterlerinin kalıtımı ve verimle ilişkileri üzerine bir araştırma. Bölge Pamuk Araştırma Enstitüsü Müdürlügüü. Adana. Yayın No: 40.

Gürel A., Akdemir H., Emiroğlu Ş.H., Kadoğlu H., Karadayı H.B. 2000. Türkiye lif bitkileri. Türkiye Ziraat Mühendisliği V. Teknik Kongresi, 17-21 Ocak, Ankara, 525-566.

Karademir E., Karademir Ç., Ekinci R., Sevilmiş U. 2015. İleri Generasyondaki Pamuk (Gossypium hirsutum L.) Hatlarında Verim ve Lif Kalite Özelliklerinin Belirlenmesi. Türkiye Tarımsal Araştırmalar Dergisi. ISSN: 2148-2306. Turk J Agric Res. (2015) 2: 100-107

Smith, C.W., Cantrell, G.R., Moser, H.S., Oakley, S.R. 1999. History of cultivar development in the United States. In Cotton: Origin, History, Technology, and Production, (C.W. Smith and Cothren J.T. Eds.) John Wiley \& Sons, pp. 99-171, New York. 